\title{
Divertor materials evaluation system (DiMES)
}

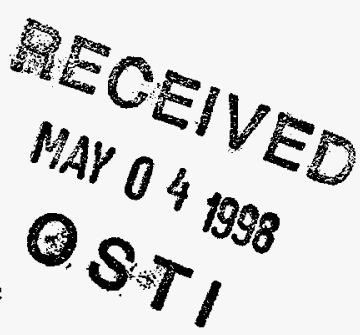

C.P.C. Wong, ${ }^{a}$ D.G. Whyte, ${ }^{b}$ R.J. Bastasz, ${ }^{c}$ J. Brooks, ${ }^{\text {d }}$ W.P. West, ${ }^{a}$ W.R. Wampler ${ }^{\mathrm{e}}$

${ }^{a}$ General Atomics, P.O. Box 85608, San Diego, California 92186-5608, U.S.A.

b University of California, San Diego, La Jolla, Califomia 92093-0021, U.S.A.

'Sandia National Laboratories, Livermore, California 9455I-0969, U.S.A

d Argonne National Laboratory, Argonne, Illinois, 60439, U.S.A.

'Sandia National Laboratories, Albuquerque, New Mexico, 87185-5800, U.S.A.

\section{Abstract}

The mission of the Divertor Materials Evaluation System (DiMES) in DIII-D is to establish an integrated data base from measurements in the divertor of a tokamak in order to address some of the ITER and fusion power reactor plasma material interaction issues. Carbon and metal coatings of $\mathrm{Be}, \mathrm{W}, \mathrm{V}$, and Mo were exposed to the steady-state outer strike point on DIII-D for 4-18 s. These short exposure times ensure controlled exposure conditions, and the extensive arrays of DIII-D divertor diagnostics provide a wellcharacterized plasma for modeling efforts. Post-exposure analysis provides a direct measure of surface material erosion rates and the amount of retained deuterium. For carbon, these results match closely with the results of accumulated carbon deposition and erosion, and the corresponding deuterium retention of long term exposure tiles in DII-D.

Deuterium retention of different materials was measured using the ${ }^{3} \mathrm{He}(\mathrm{d}, \mathrm{p}){ }^{4} \mathrm{He}$ nuclear reaction [1]. For carbon, these measurements showed peak deuterium areal density of about $8 \times 10^{18} \mathrm{D} / \mathrm{cm}^{2}$ in a co-deposited layer about $6 \mu \mathrm{m}$ deep, mainly at the usually detached inboard divertor leg. That layer of carbon near the inner divertor strike point has an atomic saturation concentration of $\mathrm{D} / \mathrm{C} \approx 0.25$, which is not significantly lower than the laboratory-measured saturation retention of 0.4 .

Under the carbon-contaminated background plasma of DIII-D, metal coatings of $\mathrm{Be}, \mathrm{V}, \mathrm{Mo}$, and $\mathrm{W}$ were exposed to the steady-state outer strike point under ELMing and 
ELM-free H-mode discharges. The rate of material erosion and deuterium retention were measured. As expected, W shows the lowest erosion rate at $0.1 \mathrm{~nm} / \mathrm{s}$ and the lowest deuterium uptake of $2 \times 10^{20} / \mathrm{m}^{2}$.

Key Words: beryllium, beryllium alloys and compounds, carbon and carbon materials, plasma facing materials, plasma-materials interaction, tungsten, tungsten alloys and compounds

\section{Introduction}

Plasma-material interaction (PMI) will play a crucial role in the design and operation of a high power magnetic confinement fusion device, directly impacting the areas of component lifetime, plasma performance, safety, vacuum pumping and fuel cycle designs [2]. The mission of DiMES is to establish an integrated PMI data base from a diverted tokamak to address ITER and power reactor PMl issues, specifically erosion, redeposition, and deuterium/tritium uptake. ITER-relevant materials, $\mathrm{C}, \mathrm{Be}, \mathrm{V}, \mathrm{Mo}$, and $\mathrm{W}$, have been exposed to provide the necessary data in the areas of plasma surface material erosion and tritium retention. These data are obtained during quiescent and transient (e.g., ELMs) events. Data obtained by DiMES is shown to be consistent with measurements taken from divertor tiles mounted in DIII-D for a full year's campaign. Along with analyzed DIII-D divertor plasma diagnostic data, they are also provided to plasma materials interaction modeling groups to help benchmark their complex codes. The relevance of these measurements to the ITER design is discussed. Finally, future tasks that can possibly be addressed by the DiMES program are mentioned.

\section{The DiMES experiment}

DiMES experiments are conducted by inserting ATJ graphite samples to the lower divertor of DIII-D as shown in Fig. 1. Thin films ( $100 \mathrm{~nm}$ thickness) of Be, V, Mo and W have been exposed by coating a small region of the sample's plasma facing surface. 


\section{DISCLAIMER}

This report was prepared as an account of work sponsored by an agency of the United States Government. Neither the United States Government nor any agency thereof, nor any of their employees, makes any warranty, express or implied, or assumes any legal liability or responsibility for the accuracy, completeness, or usefulness of any information, apparatus, product, or process disclosed, or represents that its use would not infringe privately owned rights. Reference herein to any specific commercial product, process, or service by trade name, trademark, manufacturer, or otherwise does not necessarily constitute or imply its endorsement, recommendation, or favoring by the United States Government or any agency thereof. The views and opinions of authors expressed herein do not necessarily state or reflect those of the United States Government or any agency thereof. 


\section{DISCLAIMER}

Portions of this document may be illegible electronic image products. Images are produced from the best available original document. 
During the exposure discharges, the sample is kept in the private flux region until the desired target plasma is achieved. The strike point is then swept onto the DiMES sample location. This is repeated over several shots to achieve the desired exposure time from 4-18 s [3]. Typically, the positioning control of the separatrix on the sample is accurate to within $5 \mathrm{~mm}$. Before and after the exposure, the sample is characterized to make measurements of net carbon erosion, metal film erosion and redistribution. These samples are implanted with a Si depth-marker [4]. The depth marking technique with implanted Si allows measurement of the net carbon erosion/redeposition to $\pm 10 \mathrm{~nm}$ using the technique of Rutherford Backscattering Spectroscopy (RBS) or Nuclear Reaction Analysis (NRA) [1]. Numerous DIII-D diagnostics are used to quantify the divertor plasma parameters of temperature and density, particle and heat fluxes, sputtered particle flux, and magnetic field configuration [3]. These results are supportive of ongoing modeling efforts at Argonne National Laboratory [5]. Typical plasma parameters of interest are: gas $=\mathrm{D}_{2}, \mathrm{I}_{\mathrm{p}}=1.35-$ 1.4 MA, $\mathrm{B}_{\mathrm{T}}=-1.9 \mathrm{~T}$, magnetic pitch angle at $\mathrm{OSP}=1.5-2.5^{\circ}, \mathrm{Z}_{\mathrm{eff}}=1.5$, carbon fraction in core $=1 \%-2 \%$, oxygen fraction in core $=0.1 \%-0.2 \%$. Erosion experiments have been conducted at incident heat fluxes ranging from 0.5 to $2 \mathrm{MW} / \mathrm{m}^{2}$. The surface temperature is in the range of $100^{\circ} \mathrm{C}$ to $300^{\circ} \mathrm{C}$.

\section{Carbon erosion and deuterium uptake}

Carbon samples have been exposed to the steady-state outer strike point under ELMing and ELM-free $\mathrm{H}$-mode discharges. Maximum net erosion rate as a function of incident heat flux is shown in Fig. 2. Over the power range studied, the net erosion at the outer strike point is seen to scale linearly with the incident power flux. The measured net erosion rate for $\mathrm{C}$ at a heat flux of $2 \mathrm{MW} / \mathrm{m}^{2}$ is substantial $(16 \mathrm{~nm} / \mathrm{s}=50 \mathrm{~cm} / \mathrm{burn}-\mathrm{y}$.) during ELMing $\mathrm{H}-$ mode.

Deuterium retention of different materials was measured using the ${ }^{3} \mathrm{He}(\mathrm{d}, \mathrm{p}){ }^{4} \mathrm{He}$ nuclear reaction [1]. Figure 3 shows the measured deuterium areal density overlayed for two samples which include $\mathrm{C}, \mathrm{Be}, \mathrm{V}, \mathrm{Mo}$, and $\mathrm{W}$ after exposure to outer strike point. The total deuterium fluence of $1.2-4.2 \times 10^{23} / \mathrm{m}^{2}$ in DIII-D exposure is higher than the 
saturation fluence for $\mathrm{C}, \mathrm{Be}$ and $\mathrm{W}[6]$. For the case of ITER, with a divertor surface area of about $300 \mathrm{~m}^{2}$, in-vessel saturated tritium inventory at this areal density for $\mathrm{Be}$ and $\mathrm{C}$ would be in the range one gram. This would not be a concern if the impact from erosion is insignificant. But this would not be the case for ITER.

Measurement of carbon net erosion and deuterium retention of long-term exposure tiles in DIII-D indicates a more serious problem in regions of net redeposition. The net change in the surface profile of the divertor floor from measurements before and after nine months of plasma operation is shown in Fig. 4. Accumulation of deuterium along the same area was also mapped by NRA [7,8] as shown in Fig. 4. NRA measurements showed peak deuterium areal density of about $8 \times 10^{18} \mathrm{D} / \mathrm{cm}^{2}$ in a co-deposited layer about $6 \mu \mathrm{m}$ deep, mainly at the usually detached inboard divertor leg, indicating a deuterium inventory in the divertor of about one gram [8]. That layer of carbon near the inner divertor strike point has an atomic saturation concentration of $\mathrm{D} / \mathrm{C} \approx 0.25$, which is not significantly lower than the laboratory-measured saturated retention of 0.4 , despite the He glow discharge cleaning between every discharge and regular $350^{\circ} \mathrm{C}$ bakes of the DIII-D vessel. The range of short-term exposure results are overlaid in Fig. 4 showing the location of the DiMES sample along the major radius of DIII-D lower divertor. Both carbon erosion rate and deuterium areal density match closely the long term exposure results at the outer strikepoint which is an area of net erosion and low re-deposition. Based on these results modeled for ITER dimensions and DiMES run conditions, at an estimated accumulation rate for tritium of the order of $0.01 \mathrm{~g} / \mathrm{s}$, it is likely that before a few hundred DT plasma (1000s) discharges the 1-kg in-vessel tritium inventory limit for ITER will be reached due to the co-deposition of tritium with carbon. Therefore, for the ITER design, knowledge and understanding of the distribution and rates of carbon redeposition become very important. An intense search for effective methods of in-situ tritium or carbon coating removal [2] has been initiated. 


\section{Metallic coatings}

Under the carbon-contaminated background plasma of DIII-D, metal coatings of $\mathrm{Be}, \mathrm{V}, \mathrm{Mo}$, and $\mathrm{W}$ were exposed to the steady-state outer strike point under ELMing and ELM-free $\mathrm{H}$-mode discharges. Ion beam analysis was performed on the samples before and after the exposure, and the rates of material erosion and deuterium retention were measured.. The metallic film erosion rates are derived either directly from decreases in the areal concentration of the metal films or from the integrated quantity of re-deposited metal on the surrounding graphite of the DiMES sample [1,3]. These two methods agree to within $20 \%$ validating the measurement technique and indicating that, for the case of $\mathrm{W}$, essentially all the sputtered material is re-deposited locally on the sample. At a heat flux of $0.7 \mathrm{MW} / \mathrm{m}^{2}$ and $\mathrm{T}_{\mathrm{e}}=45-70 \mathrm{eV}$, erosion rates of exposed metallic surface materials are shown in Fig. 5. This shows that the erosion rates based on simple sputtering yield calculation, assuming monoenergetic $\mathrm{D}^{+}$ion at $300 \mathrm{eV}\left(\cong 5 \mathrm{~T}_{e}\right)$ at normal incident, are consistently higher than the measured value The measured erosion rate for the exposed materials is logarithmically dependent on the atomic weight, as expected for pure materials. In general, mixed material effects are very complex and will have a large impact on surface erosion.

As expected, $W$ shows the lowest erosion rate at $0.1 \mathrm{~nm} / \mathrm{s}$. The corresponding measured peak net erosion rate of carbon is $3.7 \mathrm{~nm} / \mathrm{s}$. Modeling [5] indicates that, at these plasma conditions, the net erosion of carbon was five times less than the gross sputtering rate at the strike point, due to redeposition of carbon from the surrounding graphite divertor. Under the conditions of this experiment, the measured $\mathrm{W}$ rate is more indicative of the gross sputtrering rate, and not a net erosion that would occur in an all $\mathrm{W}$ divertor design. Based on the observed location of redeposited $W$ from the highly localized source used for these experiments, it is conservative to assume a similar $80 \%$ reduction in net erosion This would show that the net erosion rate of $\mathrm{W}$ coula be $\sim 200$ times lower than carbon, indicating that $\mathrm{W}$ may be a more suitable erosion resistant material for the reactor design. Further erosion reduction may be possible by reducing the ion temperature to less than $25 \mathrm{eV}$ [9]. However, there is always the concern of $\mathrm{W}$ impurity contamination of the 
plasma core. Results from ASDEX-Upgrade show that the migration of $\mathrm{W}$ from its divertor is acceptable [11]. The applicability of $\mathrm{W}$ as a plasma facing material is far from settled. DiMES has observed the presence of radial arc-tracks on W coatings (and not on Be) which can have significant further impact on net erosion. Similarly, projections of surface melting under disruptive conditions limit lifetime. These effects will have to be studied in more detail, while in parallel, various means to mitigate the damaging effects from disruptions should also be continued.

For beryllium, we find that the measured $\mathrm{Be}$ erosion rate is about $1 / 3$ of the predicted rate based on simple monoenergetic deuterium ion physical sputtering for the "pure" material which is similar to the results obtained by PISCES [12]. A flux of carbon atoms from the plasma deposited onto metal surfaces is expected to reduce the metal concentration at the surface through formation of a mixed surface layer thereby reducing the metal erosion [1]. The reduction in metal erosion by carbon from the plasma is still being investigated.

For V metal, which is of interest due to its low activation and high-temperature capability, the measured erosion rate is about half of that for $\mathrm{Be}$, but the retention of deuterium is twice as high as for Be as shown in Fig. 3. The higher $\mathrm{D}$ retention is probably due to the formation of vanadium hydride and the high solubility of hydrogen. Furthermore, as an initial step to study the interaction of $\mathrm{V}-4 \mathrm{Cr}-4 \mathrm{Ti}$ alloy and tokamak plasma, short-term exposure tests were conducted to study the effect of a post vent bakeout at $350^{\circ} \mathrm{C}$, when concentrations of gaseous impurities in the DIII-D chamber are the highest. Preliminary results indicate minor degradation of mechanical properties. Additional testing and microstructural characterization are in progress [12].

\section{DiMES planning}

DiMES program has been developed into a very useful facility to provide integrated plasma surface erosion and deuterium retention data to the PMI study necessary for the ITER and fusion reactor designs. However, the accumulation of necessary knowledge has 
just begun and much more has to be done. The following tasks and system up-grades are being implemented and planned for the DiMES program.

\section{DiMES sample exposure experiments:}

- Continue to support the collection and characterization of carbon dust from DIII-D.

- Continue to expose DiMES samples to higher power discharges of attached plasma.

- Expose DiMES samples to detached divertor plasma.

- Perform disruption experiment on Al metal coating and to study the movement of melted layer.

- Continue the evaluation of other ITER relevant materials.

- Continue to support the evaluation of V-alloy and W-alloy as plasma facing materials.

- Investigate the possibility of exposing relevant liquid surface material in DIII-D.

The following hardware upgrades are being planned:

- A heated DiMES sample is proposed to control the temperature of the exposed surface: This is an important parameter for both chemical erosion and deuterium retention effects.

- A midplane DiMES station is proposed to be designed in FY1998 and to be installed FY1999. When the lower divertor and mid-plane DiMES stations are operational, first wall erosion, and impurity transport and entrainment between the divertor and scrape off layer (SOL) can be studied and quantified.

\section{Conclusions}

To support the area of PMI, DiMES is providing vital data in the area of material surface erosion and tritium retention for relevant materials under exposure to well characterized tokamak divertor plasma. Carbon and metallic coatings of $\mathrm{Be}, \mathrm{V}, \mathrm{Mo}$, and $\mathrm{W}$ were exposed to the steady-state outer strike point on DIII-D. For carbon, DiMES data match closely the results of accumulated carbon deposition and erosion, and the corresponding deuterium retention of long term exposure tiles in DIII-D. These results confirm that erosion of carbon will limit the lifetime of carbon plasma facing components 
for ITER and will have significant safety impacts due to the deposition of tritium saturated carbon. During normal discharges, a W coating can have much longer life than carbon but the concerns of core contamination, erosion due to arcing and under disruptive events will have to be addressed. DiMES will continue to provide valuable data in support of the rapid growth in detailed understanding of PMI in magnetic confinement fusion devices.

\section{Acknowledgment}

This is a report of work supported by the U.S. Department of Energy under Contract Nos. DE-AC03-89ER52153, DE-AC04-94AL85000, W-31-109-ENG-38 and Grant No. DE-FG03-95ER54294.

\section{References}

[1] W.R. Wampler, R. Bastasz, D. Buchenauer, et al., J. Nucl. Mater. 233 (1995) 791797.

[2] G. Federici, personal communication, Summary of ITER Relevant Results on Plasma Wall Interaction Experiments Franco on ITER, to be published as an ITER report, 1997.

[3] D.G. Whyte, J.N. Brooks, C.P.C. Wong, et al., J. Nucl. Mater. 241-243 (1997) 660665.

[4] R. Bastasz, W.R. Wampler, J.W. Cuthbertson, et al., J. of Nucl. Mater. 220-222 310(1995) 314.

[5] T.Q. Hua and J.N. Brooks, J. Nucl. Mater. 220-222 (1995) 342.

[6] A.A. Haasz, and J.W. Davis, in: Proc. 12th Int. Conf. on Plasma Surface Interations in Controlled Fusion Devices, St. Raphael, 1996, J. Nucl. Mater.

[7] D.N. Hill, Plasma Phys, and Contr. Nucl. Fusion Research, IAEA-CN-53/G-I-E, and W.L. Hsu, personnal communication; D. Walsh, 15th D-T Materials Physics Group Meeting at Sandia National Laboratories in Livermore, Ca., Feb. 1991.

[8] P.L. Taylor, J. Fusion Energy 12 (1993) 33. 
-[9] W. Eckstein and J. Laszlo, J. Nucl. Mater. 183 (1991) 19.

[10] K. Krieger et al., in: Proc. 12th Int. Conf. on Plasma Surface Interactions in Controlled Fusion Devices, St . Raphael, France, May 20-24, 1996; to be published in J. Nucl. Mater.

[11] R. Boivin, R. Doerner, R.W. Conn, Y. Hirooka, S. Luckhardt, D. Sze, J. Won, "PISCES-B Beryllium Mixed Material Experiments on Plasma Surface Interactions: Implications for ITER”, Research Report UCSD-ENG-019 (1996), Febraury 1996.

[12] H. Tsai, H.M. Chung, D.L. Smith, W.R. Johnson and J.P. Smith, "Performance of V-4Cr-4Ti Material Exposed to DIII-D Tokamak Environment,"' Fusion Materials Semiannual Progress Report, DOE/ER-0313/21 (1997) p. 10. 


\section{Figure Caption}

Fig. 1. Divertor Material Evaluation System (DiMES) in DIII-D

Fig. 2. Maximum carbon net erosion as a function of incident heat flux.

Fig. 3. Comparison of deuterium areal density of after exposure of two samples to study C, Be, V, Mo and W surfaces in the DIII-D divertor. Shaded areas show the location of metallic coatings, as labeled. The unshaded area is for the graphite substrate.

Fig. 4. Erosion and deuterium retention results from long-term exposure of DIII-D tiles and from DiMES experiments.

Fig. 5. Measured erosion rate of $\mathrm{Be}, \mathrm{V}, \mathrm{Mo}$ and $\mathrm{W}$, at a heat flux of $0.7 \mathrm{MW} / \mathrm{m}^{2}$ and $\mathrm{T}_{\mathrm{e}}=$ $45-70 \mathrm{eV}$. Also shown is the gross sputtering rate calculated from the measured ion flux and electron temperature, assuming an incident energy of $3 \mathrm{kT}$. (Since no data was avai lable for $\mathrm{V}$, the sputtering yield of $\mathrm{Ti}$.) 


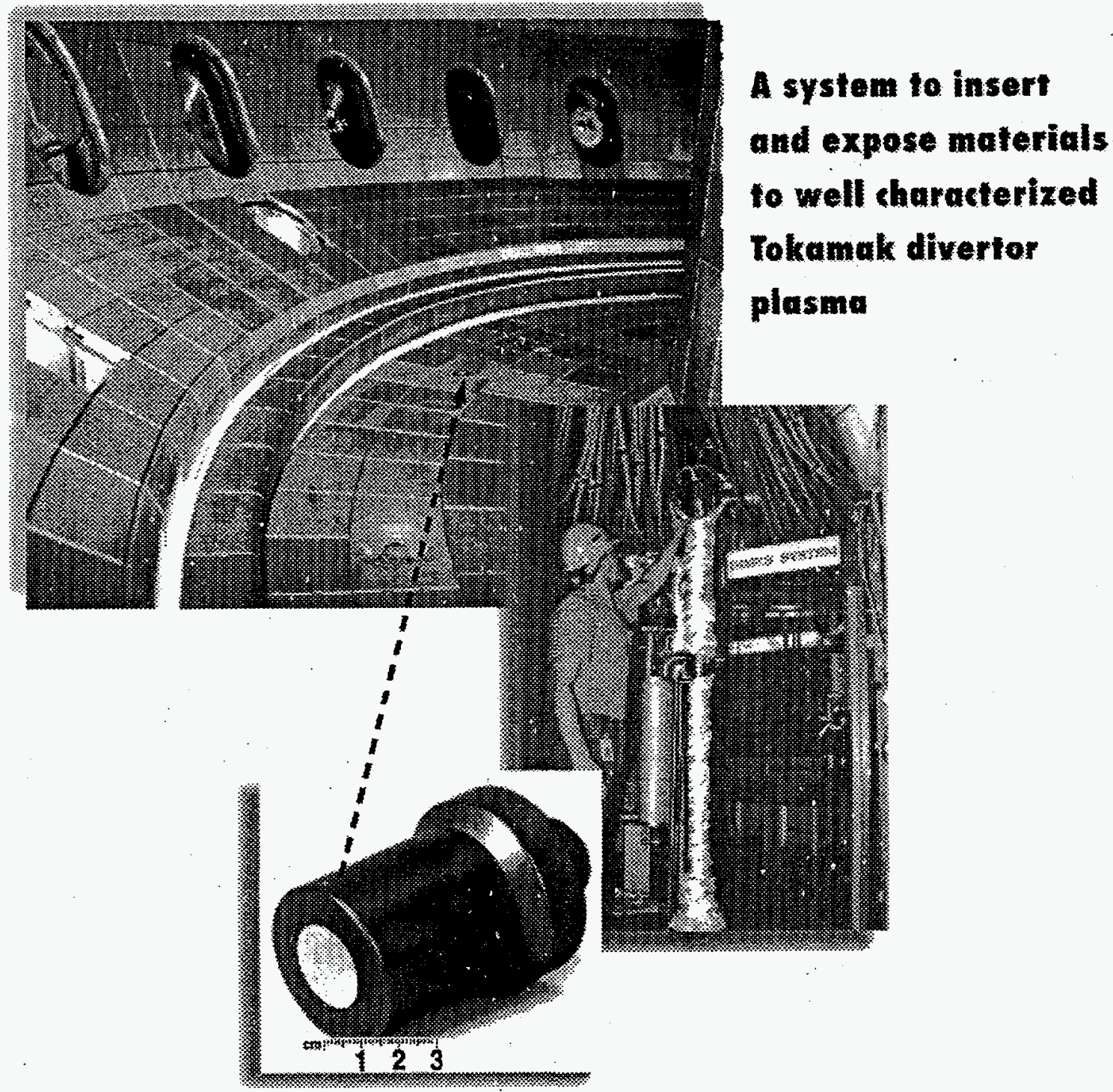




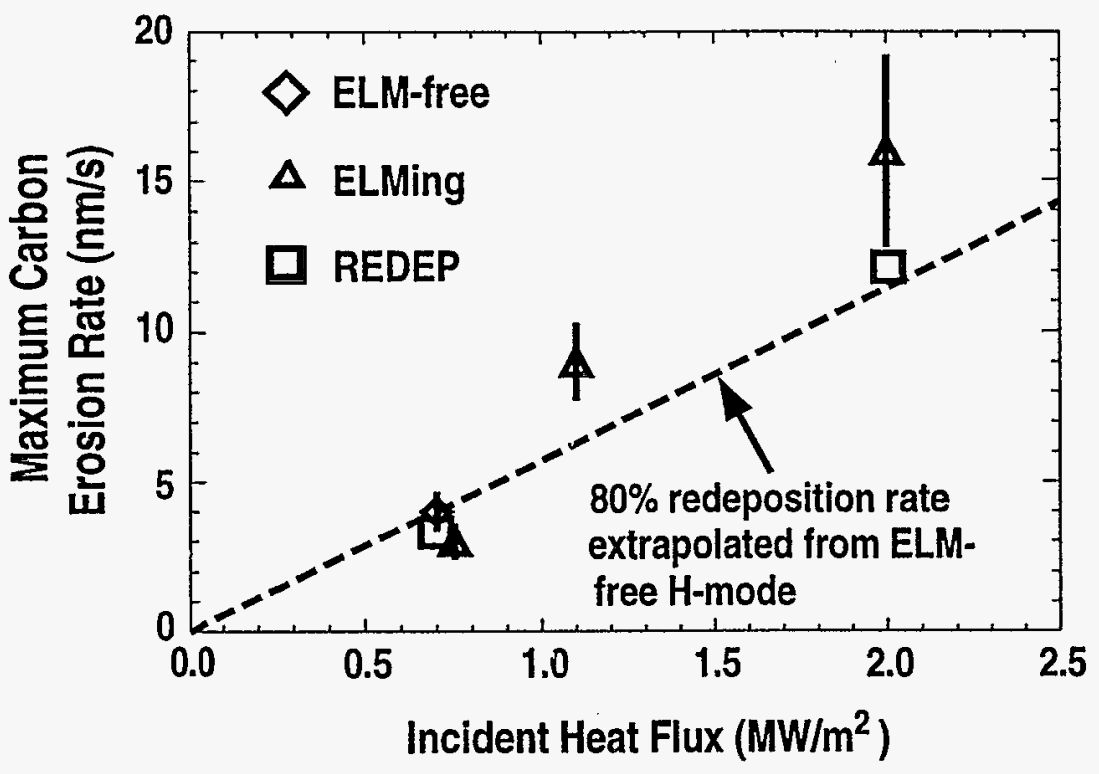

C.P.C. Wong, Fig. 2 


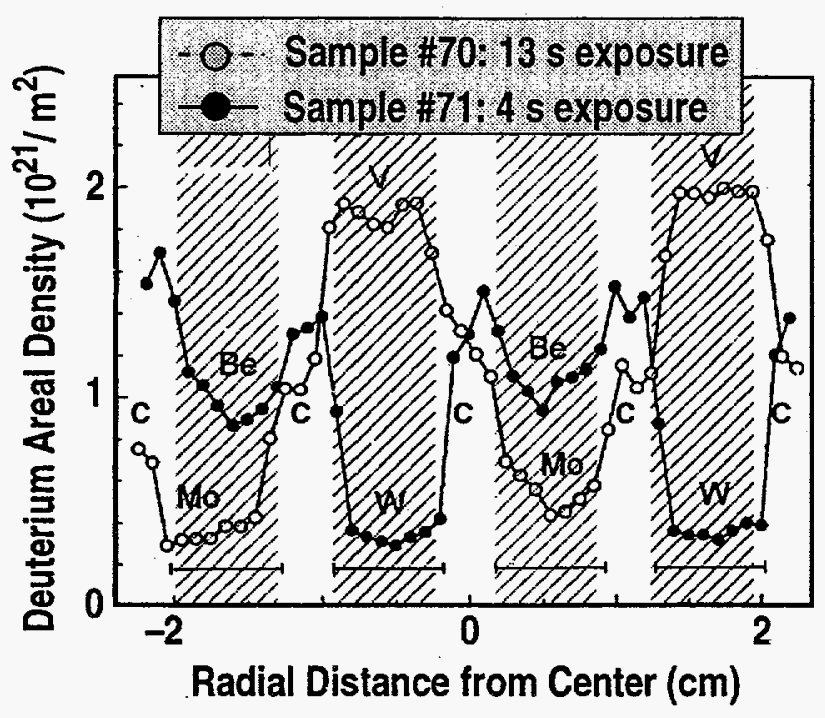

C.P.C. Wong Fig. 3 

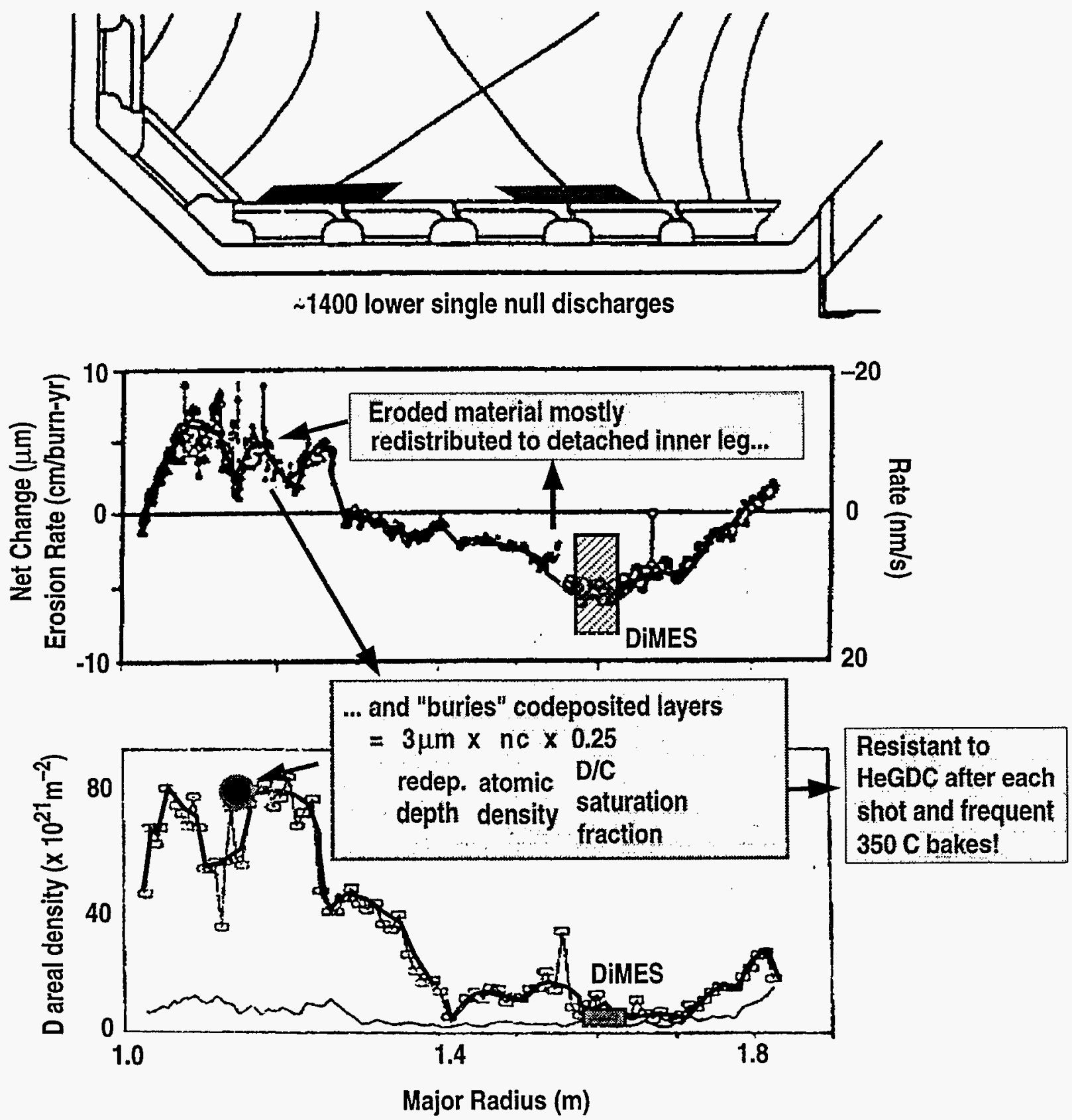


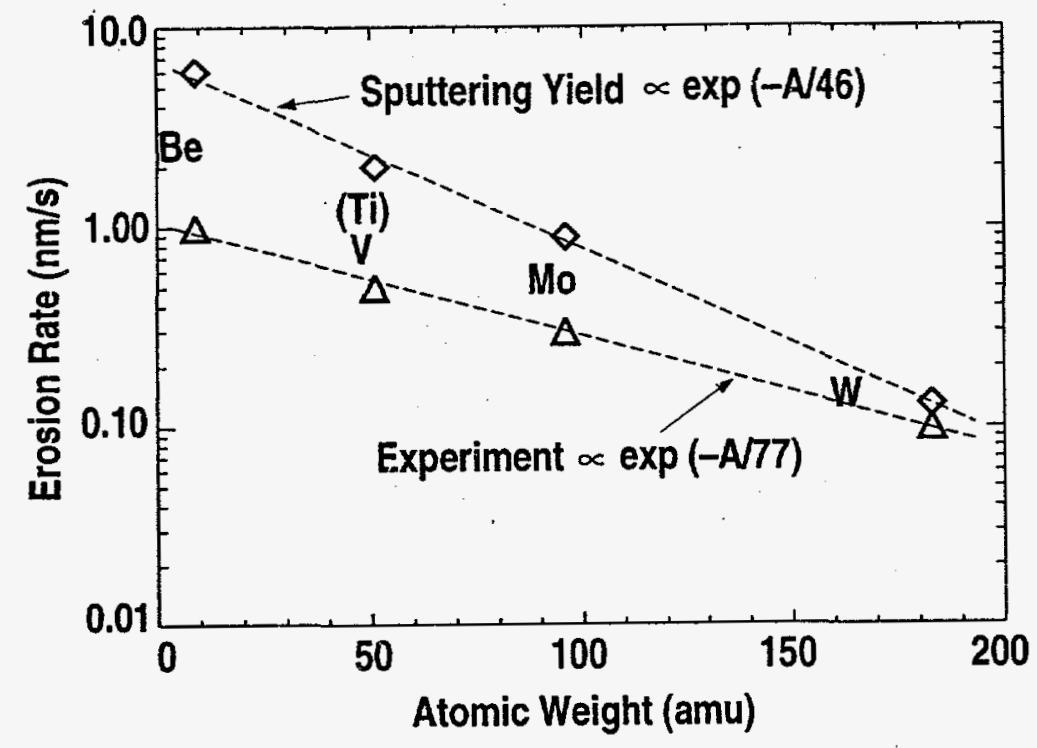

C.P.C. Wong Fig. 5 